\title{
4-Chloro-6-pyrimidinylferrocene modified silica gel: a novel multiple-function stationary phase for mixed-mode chromatography
}

\author{
Lijun Qiao ${ }^{\text {a }}$, Xiaohua Zhou ${ }^{\text {a }}$, Yanhao Zhang ${ }^{\text {a }}$, Ajuan Yu ${ }^{\mathrm{a}, *}$, Kai Hu ${ }^{\mathrm{b}}$, Shusheng Zhang ${ }^{\mathrm{a}, *}$, \\ Yangjie $\mathrm{Wu}^{\text {a }}$
}

\begin{abstract}
${ }^{a}$ College of Chemistry and Molecular Engineering, Key Laboratory of Chemical Biology and Organic Chemistry of Henan, Zhengzhou University, Zhengzhou 450052, P. R. China; Fax: +86 3716776 3224; E-mail addresses: yuajuan@zzu.edu.cn, zsszz@ 126.com

${ }^{\mathrm{b}}$ Henan University of Traditional Chinese Medicine, Zhengzhou 450008, P. R. China
\end{abstract}

\begin{abstract}
A novel multi-function and mixed-mode stationary phase based on 4-chloro-6-pyrimidinylferrocene modified silica $(\mathrm{NFcS})$ was synthesized and characterized by infrared spectroscopy, elemental analysis and thermogravimetric analysis. Linear solvation energy relationship method was successfully employed to evaluate the new phase with a set of 27 solutes including aromatic and aliphatic compounds. Multiple mechanisms including hydrophobic, $\pi-\pi$, hydrogen-bonding, charge-transfer, acid-base equilibrium and anion-exchange interactions are involved. Based on these interactions, successful separation could be achieved among polycyclic aromtic hydrocarbons, mono-substituted benzenes, aromatic amines, phenols, quinolines, pyridines and nucleosides in reversed-phase (RP) or normal-phase (NP) chromatography. Inorganic anions were also shown to be individually separated in anion-exchange chromatography by using the same column. Moreover, the results here also demonstrated that $\mathrm{NFcS}$ based stationary phase could effectively reduce the adverse effect of residual silanol in the separation process. Such stationary phase with characteristics of multi-interaction mechanism and mixed-mode separation is potential for the analysis of complex samples. The NFcS column was successfully employed for the analysis of plant growth regulators in Fruit.
\end{abstract}

Keywords: Ferrocene stationary phase; Muti-function; Mixed-mode; Linear solvation energy relationship; Retention mechanism.

\section{Introduction}

Recently mixed-mode chromatography has been shown to be a flexible and versatile method for the simultaneous separation of highly mixed classes of analytes, especially ions and organic compounds [1]. In principle, the mixed-mode stationary phases which were chemically modified by functional groups, were designed by combining two or more separation mechanisms such as non-specific hydrophobic interactions and specific electrostatic interactions. Nitrogen compounds such as amine [1-3], pyridine [4-7], 8-quinolinol [8], imidazolium [9-13], quinuclidine [14-16, 17-22] were often immobilized to silica gel through a coupling carbon chain to achieve a mixed-mode stationary phase. Since the phases combine hydrophobic binding domains and terminal anion exchange moiety, they exhibit both RP and anion-exchange chromatographic modes to achieve complementary selectivities. Owning to its fantastic chromatographic performance, mixed-mode chromatography stationary phases mentioned above are now used to separate a wide range of organic [3-12] and inorganic anions [3, 5-9, 11] besides biomolecules [10, 
$12,15-16,18-20,22]$.

Since Delville [23-24] and Zuo [25-26] reported the application of ferrocene as the stationary phase, it has attracted extensive attention in liquid chromatography [27] due to its varieties of separation mechanisms, including hydrophobic, hydrogen bonding, $\pi$ - $\pi$, dipole-dipole and charge-transfer interactions. Complexing properties of ferrocene receptors depend mainly on the type and arrangement of binding site. Since the heteroatoms such as nitrogen have different electronic and steric nature from carbon, introduction of heteroatoms onto the aromatic ring positions of ferrocenes would result in a fundamentally new class of ferrocene molecules. More importantly, nitrogen atoms in ferrocenes are ready to be protonated as positively charged cations under acidic or near neutral conditions, electrostatic interactions between the protonated ferrocene molecules and anion analytes may occur. Thus, the new ferrocene molecules might serve as chromatographic mediums to increase separation selectivity with multiple retention mechanisms such as ion-exchange interaction, and achieve multimodal separations including reversed-phase (RP) and normal-phase (NP) chromatography modes. Our group has been comitted to the research of ferrocene stationary phases and several novel multi-interaction and mixed-mode stationary phase based on ferrocene complexes modified silica gel has been synthesized in our laboratory [28-29]. However, there is no report showing that ferrocene stationary phase may be equally selective toward inorganic anions because of the absence of anion exchange moiety in ferrocene matrix molecule.

In this study, we extended our previous work by describing the synthesis and chromatographic performance of a novel mixed-mode 4-chloro-6-pyrimidinylferrocene modified silica stationary phase (NFcS, Fig. 1). In contrast with presented ferrocene in which the metallocenes are linked with carbonyl, one goal of this work was mainly to evaluate the recognition performance after the introduction of nitrogen heterocyclic in the ferrocene molecule. Its retention property was elucidated by linear solvation energy relationship (LSER) study with a set of 27 solutes. The NFcS could be utilized as a RP or NP stationary phase for the separation of neutral solutes, as well as an anion-exchange stationary phase for the separation of inorganic anions, which indicates its multi-interaction mechanism and mixed-modal characteristic, and its analytical prospect for complex samples. The excellent symmetry of the peaks of several basic solutes such as aromatic amines, quinolines, pyridines and nucleosides indicates that the new phase has a masking effect for silanol groups. The column has been successfully employed for the analysis of for chlorfenuron and benzthiazuron in grapes.

Fig. 1.

\section{Experimental}

\subsection{Apparatus and reagents}

Chromatographic analyses were carried out by using an Agilent 1200 series system equipped with a 1200 model quaternary pump, a G1314A model multiple wavelength UV-Vis detector, a G1316A model thermostated column compartment, a 1332A model vacuum degasser and an Agilent Chemstation B.03.02 Patch data processor. The home-made ferrocene column was slurry packed into a bare stainless steel tube column $(150 \mathrm{~mm} \times 4.6 \mathrm{~mm}$ i.d. Innosep scientific Co. Ltd., Zhengzhou, China) using tetrachloromethane as slurry solvent and methanol as propulsive solvent. A CGY-100B pneumatic pump (Bejing Fusiyuan Mechanical Processing Factory, Beijing, China) was used with packing pressure of $50 \mathrm{MPa}$. Elemental analysis was performed with a Flash EA 1112 elemental analyzer. ${ }^{1} \mathrm{H}$ NMR and ${ }^{13} \mathrm{C}$ NMR spectra were recorded with a Bruker $400 \mathrm{MHz}$ 
spectrometer in $\mathrm{CDCl}_{3}$. IR spectra were recorded with a Bruker Vector 22 instrument. Thermal gravimetric analysis (TGA) was carried out on a Shimadzu DT-40 thermal analyzer, the analysis was performed from $40{ }^{\circ} \mathrm{C}$ to $650{ }^{\circ} \mathrm{C}$ at heating rate of $10{ }^{\circ} \mathrm{C} / \mathrm{min}$ in argon atmosphere with a gas flow rate of $20 \mathrm{~mL} \mathrm{~min}^{-1}$.

Silica gel (with particle size of $5 \mu \mathrm{m}$, pore size of $100 \AA$ and specific surface area of $300 \mathrm{~m}^{2} / \mathrm{g}$ ) was provided by Lanzhou Institute of Chemical Physics, Chinese Academy of Science (Lanzhou, China). 3-Aminopropyltriethoxysilane (KH-550) was purchased from Jingchun Chemical Reagent Co. Ltd. (Shanghai, China). 4-Chloro-6-pyrimidinylferrocene was synthesized according to published procedures [30-31]. Unless specified otherwise, all chemicals and solvents were of analytical reagent grade and purchased from the Beijing Chemical Plant (Beijing, China). Acetonitrile, hexane and isopropanol were of HPLC grade and purchased from the luzhong Reagent Plant of Shanghai (Shanghai, China). Water was purified using Milli-Q purification equipment.

\subsection{Preparation of 4-chloro-6-pyrimidinylferrocene functionalized silica}

\subsubsection{Sililation of silica gel}

Silica was immersed in hydrochloric acid/water solution $(1: 1, \mathrm{v} / \mathrm{v})$ for $24 \mathrm{~h}$ and then the mixture was stirred and refluxed for $24 \mathrm{~h}$, then washed with water and dried under vacuum at $120{ }^{\circ} \mathrm{C}$ for 8 h. In a round-bottomed flask equipped with a reflux condenser and a gas inlet valve, $6.0 \mathrm{~g}$ activated silica was dispersed in toluene. After the addition of $10 \mathrm{~mL}$ 3-aminopropyltriethoxysilane, the mixture was stirred and refluxed for $24 \mathrm{~h}$ under a nitrogen atmosphere before being cooled to room temperature. The suspension was filtered, washed successively with toluene, acetone, methanol and acetone/water (v/v, 1/1), and then dried at $100{ }^{\circ} \mathrm{C}$ under vacuum for $12 \mathrm{~h}$. Finally, 3-aminopropyltriethoxyl-bonded silica gel (ABS) was obtained and used as a precursor in the following reaction.

\subsubsection{Synthesis of 4-chloro-6-pyrimidinylferrocene}

4-Chloro-6-pyrimidinylferrocene was synthesized according to the reported procedures [30-31]. A solution of mercuric acetate $(33 \mathrm{mmol})$ in absolute methanol $(85 \mathrm{~mL})$ was added dropwise to a stirred solution of ferrocene $(67 \mathrm{mmol})$ in dry benzene $(50 \mathrm{~mL})$. The reaction was continued under a nitrogen atmosphere at room temperature for $10 \mathrm{~h}$, and then lithium chloride $(70 \mathrm{mmol})$ in a 1:1 ethanol-water $(20 \mathrm{~mL})$ mixture was added dropwise. The resulting orange suspension was stirred at room temperature for $2 \mathrm{~h}$, then heated under reflux for $1 \mathrm{~h}$ and was finally collected, placed in a Soxhlet, extracted with dichloromethane. The dichloromethane extract was washed thoroughly with water and dried over sodium sulfate. After removal of the solvent, the solid residue was sublimed in vacuo to remove unchanged ferrocene. In this manner ferrocene was recovered. The unsublimed portion gave on recrystallisation from dichloromethane-petroleum ether, chloromercuriferrocene (43\%) as golden platelets.

In a flask equipped with reflux condenser and gas inlet chloromercuriferrocene (1mmol), 4, 6-dichloropyrimidine (1.1 mmol), NaI (2 mmol) and $\mathrm{Pd}\left(\mathrm{PPh}_{3}\right)_{4}(0.05 \mathrm{mmol}), 18 \mathrm{~mL}$ absolute THF and $12 \mathrm{~mL}$ absolute acetone were placed under $\mathrm{N}_{2}$ atmosphere. The reaction mixture was then placed in an oil bath and heated at $80{ }^{\circ} \mathrm{C}$ for $6 \mathrm{~h}$, cooled and quenched with water. The organic layer was separated and the aqueous layer was extracted with dichloromethane. The combined organic layers were washed with water, dried with $\mathrm{MgSO}_{4}$ and then filtered. Evaporation of the solvent gave the rude product. Next, it was separated by passing through a short silica gel column with $\mathrm{CH}_{2} \mathrm{Cl}_{2}$ /petroleum ether solution (2:1) as eluent. The second band was collected and afforded 
the red solid.

\subsubsection{Preparation of 4-chloro-6-pyrimidinylferrocene-bonded silica stationary phase}

The schematic diagram of synthetic procedure for ferrocene-bonded silica gel stationary phase is shown in Fig. 2. Details of the bonding procedure are as follows. ABS was prepared by a method as previously described to be used as a precursor in the following reaction below. In a round-bottomed flask equipped with a magnetic stirrer and a gas inlet valve, a mixture of $\mathrm{ABS}$ (3 $\mathrm{g}), \mathrm{K}_{2} \mathrm{CO}_{3}(0.62 \mathrm{~g})$, 4-chloro-6-pyrimidinylferrocene ( $1 \mathrm{~g}$ ) and diisopropyl ethyl amine (4 mL) in tetrahydrofuran $(80 \mathrm{~mL})$ was stirred for $48 \mathrm{~h}$ under nitrogen atmosphere. The suspension was filtered, and washed subsequently with toluene, acetone, methanol and water. Then 4-chloro-6pyrimidinylferrocene bonded silicastationary phase was dried under vacuum at $60{ }^{\circ} \mathrm{C}$ for $12 \mathrm{~h}$ prior to packing or characterization by FTIR, EA and TGA.

Fig. 2.

\subsection{Chromatographic procedures}

The bonded stationary phase was packed into $150 \mathrm{~mm} \times 4.6 \mathrm{~mm}$ i. d. stainless steel columns according to a slurry packing procedure by using methanol as propulsive solvent (40 MPa, $2 \mathrm{~h}$ ). Acetonitrile- $\mathrm{H}_{2} \mathrm{O}$ in RP mode and hexane-isopropanol in NP mode were used as the mobile phases. Each group of the analytes used as probes was dissolved in methanol to yield a stock solution of $500 \mu \mathrm{g} / \mathrm{mL}$. The working solutions were prepared by diluting each stock solution in the mobile phase to form the desired concentrations in the range of $5-100 \mu \mathrm{m} / \mathrm{mL}$, and $20 \mu \mathrm{L}$ of the solution was injected onto the chromatographic column. All the test mixtures were analyzed at 30 ${ }^{\circ} \mathrm{C}$ at $254 \mathrm{~nm}$ or $260 \mathrm{~nm}$. Mobile phase was filtered through a $0.45 \mu \mathrm{m}$ nylon membrane filter prior to use. Dead time was the signal of mobile phase. All measurements were performed in triplicate.

\section{Results and discussion}

\subsection{Characterization of $\mathrm{NFCS}$ stationary phase}

In IR spectra of NFcSi (Fig. S1), the bands at 2937 and $2887 \mathrm{~cm}^{-1}$ are assigned to the stretching vibration of $-\mathrm{CH}_{2}$ - groups. The absorption bands of carbon-carbon double bond and carbon-nitrogen double bonds in pyrimidine ring appearing at 1449, 1525 and $1608 \mathrm{~cm}^{-1}$ confirmed that the pyrimidinyl ligand was successfully immobilized on silica gel.

Quantitative determination of the packing material was achieved by elemental analysis. Elemental analysis results showed that the content of $\mathrm{C}, \mathrm{H}$ and $\mathrm{N}$ in $\mathrm{ABS}$ was $4.08 \%, 1.08 \%$ and $1.35 \%$, respectively; the $\mathrm{C}, \mathrm{H}$ and $\mathrm{N}$ in $\mathrm{NFcS}$ was $9.12 \%, 1.61 \%$ and $1.45 \%$, respectively. The bonding amount of 4-chloro-6-pyrimidinylferrocene was about $300 \mu \mathrm{mol} \mathrm{g}^{-1}$ based on the change of carbon content. Both the IR spectra and the elemental analysis results indicate successful preparation of $\mathrm{NFcS}$.

TG analysis curve (Fig. S2) showed the weight loss temperature of NFcS was higher than 326 ${ }^{\circ} \mathrm{C}$, indicating the packing material possessed better thermal stability and chemical stability [29]. The total weight loss was $8.37 \%$ for $\mathrm{NFcS}$ in the temperature range of $20-680{ }^{\circ} \mathrm{C}$, which was attributed to the breakage of pyrimidinyl ferrocene group bonded on the silica-gel surface together with the con-densation of remaining silanol groups.

\subsection{LSER analysis}

The chromatographic property may be greatly influenced by the intermolecular interactions among stationary phase, analytes and mobile phase, so it is beneficial and necessary to evaluate the interactions by a qualitative and quantitative approach. LSER method has been regarded as an effective means to investigate the properties of HPLC stationary phase [26, 32-33]. To gain a 
deeper insight into the chromatographic behaviors of NFcS, LSER model [34-35] was introduced to elucidate the separation mechanisms of the new phase.

Table 1 shows the 27 solutes that carefully selected from Ref. [36], which covers the non-polar and polar ones (basic and acidic). Unsuitable selection of the solutes may increase the uncertainty of LSER coefficient, or cause more serious multiple coordinated variation. The issue of cross-correlations between $R_{2}, \pi^{\mathrm{H} 2}, \Sigma \alpha^{\mathrm{H} 2}, \Sigma \beta^{\mathrm{H} 2}$ and $V_{x}$ was examined to verify the limitation of LSER induced by potential covariance of solute descriptors. Table 2 shows the cross-correlations matrix of the solute descriptors. No occurrence of significant correlation between each pair was observed. Nevertheless, there is minute correlation between $R_{2}$ and $\pi^{\mathrm{H} 2}$, which may be because both the descriptors reflect the solute polarizability and it is sensitive to the presence of $\pi$-electron [37-38]. In addition, $R_{2}$ seems to be somewhat correlated to $V_{x}$, which can be attributed to the solute's volume usually has a positive correlation with the number of double bonds. In general, the low correlation coefficients (less than 0.63 in Table 1) confirm the suitability of chosen set of solutes for employment with the LSER study.

\section{Table 1}

The LSER regression coefficients of $\mathrm{NFcS}$ and the referred ODS stationary phase were characterized under similar system conditions and are listed in Table 3. Evaluation of the LSER model was performed by comparing the experimentally-determined $\log k$ values $\left(\log k_{(\exp )}\right)$ with the calculated values $\left(\log k_{(\text {calc) }}\right)$. Fig. 3 shows the results in $80 \%$ acetonitrile as a representative example. Good linear fitting between $\log k_{(\mathrm{exp})}$ and $\log k_{\text {(calc) }}$ was observed (correlation coefficient > 0.95), confirming the competence of selected solutes in specifying the interactions between solutes and the stationary phases under reverse-phase condition.

In the LSER equation, the positive or negative sign of the coefficient indicates the strength of interaction between mobile phase and stationary phase. The negative coefficients reveal higher affinity of acetonitrile-water for the solute concerning the dipolarity/polarizability and hydrogen bonding interactions. On the other hand, positive coefficients stand for stronger molecular interactions in the stationary phase than in mobile phase.

The $v$ coefficient reflects the difference in the mobile and stationary phase cohesiveness/dispersiveness complementary to the solute size. The $v$ coefficient is influenced by two factors, which are cavity formation and dispersion interaction. Table 3 shows that the $v$ coefficient of $\mathrm{NFCS}$ is negative, suggesting that $\mathrm{NFCS}$ is less hydrophobic than mobile phase and less hydrophobic than ODS. The smaller $v$ coefficients of the aromatic phases (NFcS) likely result from a very high sorption of acetonitrile from the mobile phase.

\section{Table 2}

The $r$ coefficient is a correction factor to the dipolarity/polarizability term (the $s$ coefficient) and reflects the tendency of the system to interact with the solute through $\pi$ and $n$ - electron pairs [38]. The $r$ coefficients are either nearly zero or positive. A positive $r$ coefficient implies that a stationary phase has more $\pi-\pi$ interactions with the solute than does the mobile phase. With the increase of acetonitrile content in the mobile phase, the $r$ values of NFcS increase, indicating the electron-involved interactions of $\mathrm{NFcS}$ become weaker with the increase of water in mobile phase.

\section{Table 3}

The $s$ coefficient is a measure of dipolar interaction discrepancy of stationary phase and mobile phase with the solute. The $s$ coefficient of NFcS is small but positive, indicating the difference of dipolarity/polarizability between the mobile and stationary phases is quite small, and the dipolar 
solutes only slightly prefer the stationary phase over the mobile. The smaller positive $s$ value indicates the higher dipolarity/polarizability of NFcS over ODS, which can be explicated by the chemical properties of the two aromatic cyclopentadienyls, aza-groups and the residual silanol on $\mathrm{NFcS}$. The positive $s$ coefficient is usually the character of normal phase. So NFcS also has a little properties of normal phase. It indicates that $\mathrm{NFcS}$ can be also used in normal phase condition. The study of Zuo [26] may confirm this. Moreover, the $s$ coefficient value (close to zero, tend to be more positive) ascends with the increasing acetonitrile content in the mobile phase, implying that the increase of acetonitrile content weakens the difference in dipolarity/polarizability between the mobile and stationary phases.

The $a$ and $b$ coefficients represent the difference between mobile and stationary phases in HBD acidity and HBA basicity, respectively. As can be seen from Table 3, NFcS possesses positive $a$ and $b$ coefficients. It indicates it has a much stronger HBD ability than ODS in the mobile phases investigated. The stronger acidity of NFcS may arise from the stronger hydrogen bond donor groups (nitrogen heterocyclic and amino groups), sorbed mobile-phase components and accessible silanol groups on the support surface. It also indicates has a much stronger HBA ability than ODS in the mobile phases.

From the above LSER results, it can be concluded that NFcS possesses reversed phase and normal phase chromatography properties, and the separation process is a synergistic effect including hydrogen bonding, $\pi-\pi$ and $n-\pi$ interactions.

Fig. 3.

\subsection{Chromatographic behavior of $N F c S$}

\subsubsection{Separation of PAHs and mono-substituted benzenes}

To understand the role of hydrophobic interaction in the retention of solutes, a comparative study was conducted between the NFcS and ODS using same solute probes including polycyclic aromatic hydrocarbons (PAHs) and mono-substituted benzenes (Table 4). Fig. 4 showed the typical chromatograms of PAHs on NFcS column in NP-HPLC and RP-HPLC conditions, respectively. It can be seen from Fig. 4 and Table 4 that the elution order of analytes on NFcS was the same as that on ODS, and the $k$ values increased with the increase of hydrophobicity. Meanwhile, the $k$ values of six PAHs declined with increase of methanol content in the mobile phase (Fig. 5). These results were in accordance with reversed-phase separation mechanism, and indicated that hydrophobic interaction between the NFcS stationary phase and PAHs played an important role in the separation. On the other hand, the retention times of PAHs and mono-substituted benzenes on NFcS stationary phase were extremely shorter than those on ODS, which indicated that the hydrophobic interaction on $\mathrm{NFcS}$ was weaker than the latter. But the former had advantage in the rapid analysis of the above mentioned nonpolar aromatics.

Fig. 4.

\section{Table 4}

\section{Fig. 5.}

\subsubsection{Symmetrical separations of organic basic compounds}

Reversed phase chromatography with silica-based C18 stationary phase is the most popular and commonly used separation mode. However, it still remains a big challenge for conventional C18 stationary phases to overcome the negative effect of residual silanol groups on the separation of basic compounds. Strategies using buffered mobile phase [39] and end-capping treatment have been developed to eliminate these undesirable properties. Besides, n-alkylbonded silica with 
embedded polar functional groups such as amide [40], urea [41], pyridine [42] and imidazole [9], which has been attracting attention as another approach to improve peak shape and reproducibility. This is often explained by the hydration layer on silica surface or the competitive interaction between its polar functional groups and silanols on silica. In fact, $\mathrm{N}$-alkyl pyrimidinylferrocene is a class of alkali. The nitrogen in the pyrimidinyl can combine with $\mathrm{H}^{+}$to form a cation and can also generate a hydrogen bond with the hydrogen of silanol by lone pair electrons, which could provide exclusion effect on basic cmpounds. Thus, we expect that the negative effect of residual silanol groups in NFcS may be effectively masked while separating basic compounds. In this section, organic basic compounds including anilines, quinolines, pyridines and nucleosides were selected to show the masking effect of NFcS phase. Retention factors $(k)$ of the analytes were calculated under the optimized chromatographic conditions, and listed in Table 4. Excellent separations of pyridines, anilines, quinolines and nucleosides mixtures with symmetrical peaks can be achieved simply by adjusting the percentage of acetonitrile in the unbufferred mobile phase (acetonitrile/water).

Fig. 6 showed the typical chromatogram for amine mixture on $\mathrm{NFcS}$ column with 10/90 (v/v) acetonitrile/water and 70/30 (v/v) hexane/isopropyl alcohol, respectively. The five anilines can be effectively separated on NFCS column in RP-HPLC and NP-HPLC. NFcS phase exhibited the highest retention power and selectivity towards such analytes. A comparative study was carried out on ODS stationary phase under the same chromatographic conditions in reversed-phase mode (Table 4). Obviously, on ODS phase the elution of the five aromatic amines was aniline, 4-nitroaniline, benzidine, N, N-dimethyl, diphenylamine, while N, N-dimethyl was eluted before 4-nitroaniline and benzidine in RP conditions on NFcS column. The charge-transfer interaction resulting from nitro group and hydrogen interaction may be responsible for the increase in retention of 4-nitroaniline and benzidine. In NP mode, strong retention of benzidine was observed, which may be explained by the fact that it has two amino groups and has larger hydrogen interactions with the NFcS. It was confirmed that the retention mechanism of the new stationary phase was ascribed to multi-interactions, like hydrophobic, $\pi$ - $\pi$, charge-transfer as well as hydrogen interactions.

\section{Fig. 6.}

Methanol and acetonitrile are the most common organic modifiers of mobile phase in RP-HPLC. Methanol has stronger H-bonding donating ability and less lipophilicity than acetonitrile. Acetonitrile is an electron rich organic modifier, which could suppress the $\pi-\pi$ interactions between the analyte and the stationary phase. The selectivity and retention behaviors of NFcS could be influenced using different organic modifiers owing to different adsorptions of the organic modifier on the adsorbent surface [43]. As shown in Fig. 7, with increasing acetonitrile content in the eluent the retentions of anilines first decrease then increase. The $\mathrm{NFcS}$ phase seems to show hydrophilic interaction chromatographic mode using acetonitrile as organic modifier.

Fig. 7.

\subsubsection{Separation of phenols}

The test mixture composed of resorcinol, 1-naphthol, 2-cresol and 3-nitrophenol was investigated on $\mathrm{NFcS}$ in reversed-phase conditions. Through the examination of mobile phase compositions for separation of phenols, four phenols mixture could be successfully separated on $\mathrm{NFcS}$ column with unbuffered methanol-water $(60 / 40, \mathrm{v} / \mathrm{v})$ as the isocratic elution mobile phase (Fig. 8). The retention factors of phenols were listed in Table 4 under different chromatographic conditions. Obviously, the elution order of compounds on NFcS phase was not in agreement with 
that on ODS phase in RP-HPLC. The retention of phenols increased with their hydrophobicity except 2-cresol and 3-nitrophenol.

\section{Fig. 8.}

The strongest retention of NFcS column for 3-nitrophenol, as compared with ODS column, was likely due to the fact that the acid-base equilibrium between the hydroxy group of 3-nitrophenol and the amino group of $\mathrm{NFcS}$ played a significant role. The existence of electron-attracting group $\left(-\mathrm{NO}_{2}\right)$ causes the formation of acid-base equilibrium between the hydroxy group of nitrophenol and amino group of NFcS. In comparison with 3-nitrophenol, 2-cresol was likely to form weaker acid-base equilibrium interaction with amino groups on $\mathrm{NFcS}$ packing because of electrondonating substituent $\left(-\mathrm{CH}_{3}\right)$, which could be the reason why it was eluted firstly. The economical and environmental-friendly separation process on the $\mathrm{NFcS}$ column without buffer and gradient elution indicates that $\mathrm{NFCS}$ possessed the broad application prospect in the separation of phenols.

\subsubsection{Separation of inorganic anions}

In 4-chloro-6-pyrimidinylferrocene, additional anion-exchange sites may occur if the nitrogen groups are protonated, which is similar to some other stationary phases having bonded groups like phenylamine [3], pyridine [5-7], imidazole [9-12] and quinolinol [8]. Using $\mathrm{KCl}$ solution as the mobile phase, $\mathrm{NFcS}$ can also be applied as an anion exchange stationary phase. Some common inorganic anions composed of $\mathrm{IO}_{3}{ }^{-}, \mathrm{NO}_{3}{ }^{-}$and $\mathrm{SCN}^{-}$were chosen to investigate the anion-exchange characteristic of the stationary phase in anion-exchange mode. As shown in Fig. 9, inorganic anions in the mixture could be effectively separated with symmetrical peaks in $25 \mathrm{mmol} \mathrm{L}^{-1} \mathrm{KCl}$ aqueous solution. Thereby, $\mathrm{NFcS}$ presents an anion-exchange characteristic in anion-exchange chromatography.

\section{Fig. 9.}

\subsubsection{Determination of plant growth regulators in fruit sample on NFcS column}

Plant growth regulators (PGRs) play an important role in a variety of processes related to plant growth and development including cell division, organ formation, seed dormancy and so on. So PGRs are widely used in modern agricultural production. But the same as the other pesticides, PGRs also have a certain toxicity. Long term consumption of PGR residues in fruits and vegetables can make human body secretion disorder and affect the balance of metabolism. The hazardous effects of PGR residues for both food safety and human health have increasingly become the focus of worldwide attention [44]. Consequently, there is a growing interest in fast and more sensitive detection systems [45-48]. Also in this paper, we try to develop a rapid analysis of PGRs in fruits sample by simple HPLC method on NFcS column.

\section{Fig. 10.}

The grape sample smashed by soymilk machine was treated with acetonitrile and anhydrous sodium sulfate to dissociate the target analyte from the sample matrix. The mixed solution was centrifuged and the supernatant was extracted. This process was repeated and the two clear supernatants were combined. About $20 \mathrm{~mL}$ of extraction solution was rotary evaporated to about 1 $\mathrm{mL}$. The resulting liquid was filtered through $0.22 \mu \mathrm{m}$ filter and the filtrate was ready for analysis.

The linearity of benzthiazuron and forchlorfenuron was satisfactory in the range of 0.1-10 $\mu \mathrm{g} / \mathrm{mL}$. Under the optimal conditions, the linearity equations, regression coefficients $\mathrm{R}^{2}$, limits of detection (LOD) and limits of quantitation (LOQ) were listed in Table 5. The LODs (0.01-0.03 $\mu \mathrm{g} / \mathrm{mL})$ and LOQs $(0.04-0.10 \mu \mathrm{g} / \mathrm{mL})$ of the LC-UV analysis were adequate to detect residue about three times lower than the maximum residue limit (MRL) established for PGRs [49]. 
The RSD\% values of retention times and peak areas in intra- and inter-day assays for two PGRs were all below $0.15 \%$ and $0.36 \%$, which showed good precision and accuracy. The recoveries of benzthiazuron and forchlorfenuron for grape sample spiked with $0.5 \mu \mathrm{g} / \mathrm{mL}$ and $2.0 \mu \mathrm{g} / \mathrm{mL}$ were in the range of $82-91 \%$ and $85-95 \%$ with the RSDs less than $1.6 \%(n=6)$ and $2.3 \%(n=6)$, respectively. The optimized chromatogram of benzthiazuron and forchlorfenuron on NFcS column was shown in Fig. 10, from which we can see that two PGRs obtained better separation from the matrix. The residues of benzthiazuron and forchlorfenuron in grape were $53.5 \mu \mathrm{g} / \mathrm{kg}$ and $46.5 \mu \mathrm{g} / \mathrm{kg}$.

\section{Table 5}

\section{Conclusion}

The preparation and characterization of a new stationary phase based on 4-chloro-6-pyrimidinylferrocene silica gel were described. Linear solvation energy relationship method was successfully employed to evaluate the new phase with a set of 27 solutes including aromatic and aliphatic compounds. Different series of analytes including PAHs, mono-substituted benzenes, aromatic amines, phenols, quinolines, pyridines, nucleosides and inorganic anions were successfully separated on this novel multi-interaction stationary phase, respectively. The multi-interaction mechanism including hydrophobic, $\pi-\pi$, hydrogen-bonding, charge-transfer, acid-base equilibrium and anion-exchange interactions is involved in the chromatographic separation. With such characteristics of multi-interaction mechanism and mixed-mode separation, this stationary phase has a promising application in the analyses of complex samples. Another obvious characteristic of this new stationary phase is that symmetric peak shapes were obtained for the separation of anilines, quinolines, pyridines, nucleosides and phenols, due to the masking of residual silanols. Furthermore, the NFcSi column was successfully employed for the analysis of plant growth regulators in Fruit.

\section{Acknowledgements}

The authors acknowledge the support of NSFs of China $(21205107,21275133,21475119)$ for financial support of this research.

\section{References}

[1] S. Wongyai, Chromatographia 38 (1994) 485.

[2] M. G. Kiseleva, P. N. Nesterenko, J. Chromatogr. A 898 (2000) 23.

[3] M. G. Kiseleva, P. N. Nesterenko, J. Chromatogr. A 920 (2001) 87.

[4] T. Takeuchi, T. Kawasaki, L. W. Lim, Anal. Sci. 26 (2010) 511.

[5] L. M. L. A. Auler, C. R. Silva, K. E. Collins, C. H. Collins, J. Chromatogr. A 1073 (2005) 147.

[6] L. M. L. A. Auler, C. R. Silva, C. B. G. Bottoli, C. H. Collins, Talanta 84 (2011) 1174.

[7] M. Sun, J. J. Feng, S. J. Liu, C. M. Xiong, X. Liu, J. Chromatogr. A 1218 (2011) 3743,

[8] M. M. Muenter, K. C. Stokes, R. T. Obie, J. R. Jezorek, J. Chromatogr. A 844 (1999) 39.

[9] M. Sun, H. D. Qiu, L. C. Wang, X. Liu, S. X. Jiang, J. Chromatogr. A 1216 (2009) 3904.

[10] H. D. Qiu, S. X. Jiang, X. Liu, J. Chromatogr. A 1103 (2006) 265.

[11] H. D. Qiu, S. X. Jiang, X. Liu, L. Zhao, J. Chromatogr. A 1116 (2006) 46.

[12] P. F. Zhang, J. Chen, L. Jia, J. Chromatogr. A 1218 (2006) 3459.

[13] H. D. Qiu, M. Takafuji, T. Sawada, X. Liu, S. X. Jiang, H. Ihara, Chem. Commun. 46 (2010) 8740.

[14] W. Bicker, M. Lammerhofer, W. Lindner, Anal. Bioanal. Chem. 390 (2008) 263. 
[15] M. Lammerhofer, M. Richter, J. Y. Wu, R. Nogueira, W. Bicker, W. Lindner, J. Sep. Sci. 31 (2008) 2572.

[16] H. Luo, L. J. Ma, C. Paek, P. W. Carr, J. Chromatogr. A 1202 (2008) 8.

[17] W. Bicker, M. Lammerhofer, T. Keller, R. Schuhmacher, R. Krska, W. Lindner, Anal. Chem. 78 (2006) 5884.

[18] R. Nogueira, M. Lammerhofer, W. Lindner, J. Chromatogr. A 1089 (2005) 158.

[19] R. Nogueira, D. Lubda, A. Leitner, W. Bicker, N. M. Maier, M. Lammerhofer, W. Lindner, J. Sep. Sci. 29 (2006) 966.

[20] R. Dabre, N. Azad, A. Schwammle, M. Lammerhofer, W. Lindner, J. Sep. Sci. 34 (2011) 761.

[21] C. V. Hoffmann, R. Reischl, N. M. Maier, M. Lammerhofer, W. Lindner, J. Chromatogr. A 1216 (2009) 1157.

[22] M. Lammerhofer, R. Nogueira, W. Lindner, Anal. Bioanal. Chem. 400 (2011) 2517.

[23] O. Bordelanne, M. Delville, Solid State Sci. 4 (2002) 851.

[24] O. Bordelanne, M. Delville, G. Felix, C. Labrugere, A. Thienpont, C. Vidal, Chromatographia 52 (2000) 51.

[25] Q. Y. Huai, X. L. Wang, Y. M. Zuo, Chromatographia 55 (2002) 549.

[26] Q. Y. Huai, J. M. You, Q. Wang, Y. M. Zuo, Chromatographia 57 (2003) 709.

[27] H. J. Li, Z. F. Song, J. Q. Yu, Y. Li, L. Feng, Q. Y. Huai, Asian J. Chem. 26 (2014) 4465.

[28] A. J. Yu, D. P. Peng, K. Hu, A. J. Cao, J. B. Chang, Y. J. Wu, S. S. Zhang, J. Chromatogr. A 1283 (2013) 75.

[29] X. H. Zhou, X. L. Li, A. J. Cao, L. J. Qiao, A. J. Yu, S. S. Zhang, Y. J. Wu, Talanta 144 (2015) 1044.

[30] C. Imrie, C. Loubser, P. E. C. W. McCleland, J. Chem. Soc. 1 (1999) 2513.

[31] C. Xu, Y. P. Zhang, Z. Q. Wang, W. J. Fu, X. Q. Hao, Y. Xu, B. M. Ji, Chem.Commun. 46 (2010) 6852.

[32] L. He, M. Zhang, L. Liu, X. Jiang, P. Mao, L. Qu, J. Chromatogr. A 1270 (2012) 186.

[33] L. He, M. Zhang, W. Zhao, J. Liu, X. Jiang, S. Zhang, L. Qu, Talanta 89 (2012) 433.

[34] M. J. Kamlet, R. W. Taft, J. Am. Chem. Soc. 98 (1976) 377.

[35] M. J. Kamlet, R. W. Taft, J. Am. Chem. Soc. 98 (1976) 2886.

[36] L. C. Tan, P. W. Carr, M. H. Abraham, J. Chromatogr. A 752 (1996) 1.

[37] M. H. Abraham, M. Roses, C. F. Poole, S. K. Poole, J. Phys. Org. Chem. 10 (1997) 358.

[38] M. H. Abraham, Chem. Soc. Rev. 22 (1993) 73.

[39] D. V. McCalley, J. Chromatogr. A 738 (1996) 169.

[40] X. Liu, A. V. Bordunov, C. A. Pohl, J. Chromatogr. A 1119 (2006) 128.

[41] C. R. Silva, C. Airoldi, K. E. Collins, C. H. Collins, J. Chromatogr. A 1087 (2005) 29.

[42] H. Ihara, M. Fukui, T. Mimaki, A. Shundo, W. Dong, M. Derakhshan, T. Sakurai, M. Takafuji, S. Nagaoka, Anal. Chim. Acta 548 (2005) 51.

[43] F. Chan, L. Yeung, R. LoBrutto, Y. Kazakevich, J. Chromatogr. A 1082 (2005) 158.

[44] I. Celik, Y. Tuluce, Environ. Toxicol. 22 (2007) 613.

[45] Y. Izumi, A. Okazawa, T. Bamba, A. Kobayashi, E. Fukusaki, Anal. Chim. Acta 648 (2009) 215.

[46] X. D. Qing, H. L. Wu, C. C. Nie, X. F. Yan,Y. N. Li, J. Y. Wang, R. Q. Yu, Talanta 103 (2013) 86.

[47] J. Ziegler, J. Qwegwer, M. Schubert, J. L. Erickson, M. Schattat, K. Burstenbinder, C. D. Grubb, S. Abel, J. Chromatogr. A 1362 (2014) 102.

[48] Q. Lu, J. H. Wu, Q. W. Yu, Y. Q. Feng, J. Chromatogr. A 1367 (2014) 39. 
[49] J. L. Zhu, L. Yang, Z. L. Chai, B. Y. Jiang, S. W. Shang, Biological Disaster Science 36 (2013)232.

\section{Figure Captions}

Fig. 1. Chemical structure of the 4-chloro-6-pyrimidinylferrocene bonded silica stationary phase ( $\mathrm{NFCS})$.

Fig.2. Preparation scheme of the NFcS stationary phase.

Table 1 Solutes and solute descriptors.

Table 2 Variance-covariance matrix of solute descriptors used in LSER equation.

Table 3 System coefficients of NFcS and C18.

Fig. 3. Plot depicting $\log k($ calc $)$ versus $\log k(\exp )$ with $80 / 20(v / v)$ acetenitrile/water.

Fig. 4. Chromatograms of PAHs on NFcS in (a) NP-HPLC and (b) RP-HPLC condition.

Mobile phase: (a) hexane (100\%); flow rate, $1 \mathrm{~mL} / \mathrm{min}$; detection wavelength, $254 \mathrm{~nm}$; column temperature, $30^{\circ} \mathrm{C}$ (b) methanol-water $(60 / 40, \mathrm{v} / \mathrm{v})$; flow rate, $1 \mathrm{~mL} / \mathrm{min}$; detection wavelength, $254 \mathrm{~nm}$; column temperature, $30^{\circ} \mathrm{C}$. Peaks: 1 , benzene; 2 , naphthalene; 3 , phenanthrene; 4 , pyrene; 5 , chrysene; 6 , benzo[j]fluoranthene.

Table 4 Comparison of $k, \alpha$ and $R$ of analytes on NFcS and ODS.

Fig. 5. Effect of methanol content on $\log k$ of PAHs on NFcS column. Conditions: mobile phase, different methanol contents; flow rate, $1.0 \mathrm{~mL} / \mathrm{min}$; detection wavelength, $254 \mathrm{~nm}$; column temperature, $30^{\circ} \mathrm{C}$.

Fig. 6. Chromatograms of aniline mixtures on NFcS column in (a) NP-HPLC and (b) RP-HPLC conditions.

Mobile phase: (a) hexane-isopropanol (70/30, v/v); flow rate, $1 \mathrm{~mL} / \mathrm{min}$; detection wavelength, $254 \mathrm{~nm}$; column temperature, $30{ }^{\circ} \mathrm{C}$. (b) acetonitrile-water $(10 / 90, \mathrm{v} / \mathrm{v})$; flow rate, $1 \mathrm{~mL} / \mathrm{min}$; detection wavelength, $254 \mathrm{~nm}$; column temperature, $30{ }^{\circ} \mathrm{C}$. Peaks: 1 , aniline; 2, N, N-dimethyl aniline; 3, 4-nitroaniline; 4, benzidine; 5, diphenylamine.

Fig. 7. Effect of acetonitrile content on the retention of aromatic compounds. Conditions: mobile phase, different acetonitrile contents; flow rate, $1.0 \mathrm{~mL} / \mathrm{min}$; detection wavelength, $254 \mathrm{~nm}$; column temperature, $30^{\circ} \mathrm{C}$.

Fig. 8. Chromatograms of phenols on (a) ODS and (b) NFcS.

Mobile phase: methanol-water $(60 / 40$, v/v); flow rate, $1.0 \mathrm{~mL} / \mathrm{min}$; detection wavelength, $254 \mathrm{~nm}$; column temperature, $30^{\circ} \mathrm{C}$. Peaks: 1, 2-cresol; 2, resorcinol; 3, 1-naphthol; 4, 3-nitrophenol.

Fig. 9. Chromatograms of inorganic anions on $\mathrm{NFcS}$.

Mobile phase: $25 \mathrm{mmol} \mathrm{L}^{-1} \mathrm{KCl}$ aqueous solution $(\mathrm{pH} 6.8$ ), flow rate, $0.5 \mathrm{~mL} / \mathrm{min}$; detection wavelength, $210 \mathrm{~nm}$; column temperature, $30^{\circ} \mathrm{C}$. Peaks: 1 , iodate; 2 , nitrate; 3 , thiocyanate.

Fig. 10. Chromatogram of two PGRs in grapes on NFcS column.

Mobile phase: acetonitrile-water (20/80, v/v); flow rate, $1 \mathrm{~mL} / \mathrm{min}$; detection wavelength, $254 \mathrm{~nm}$; column temperature, $30{ }^{\circ} \mathrm{C}$. (a) grape; (b) spiked grape; (c) $2 \mu \mathrm{g} / \mathrm{mL}$ standard solution. Peaks: 1. benzthiazuron; 2. forchlorfenuron.

Table 5 The linearity equation, $\mathrm{R}^{2}$, LOD and LOQ of two PGRs on NFcS column. 
Table 1 Solutes and solute descriptors.

\begin{tabular}{|c|c|c|c|c|c|c|}
\hline NO. & Analytes & $R_{2}$ & $\pi^{\mathrm{H} 2}$ & $\sum a^{\mathrm{H} 2}$ & $\Sigma \beta^{\mathrm{H} 2}$ & $V x$ \\
\hline 1 & Benzaldehyde & 0.82 & 1 & 0 & 0.39 & 0.873 \\
\hline 2 & Nitrobenzene & 0.871 & 1.11 & 0 & 0.28 & 0.8906 \\
\hline 3 & Naphthalene & 1.34 & 0.92 & 0 & 0.2 & 1.0854 \\
\hline 4 & Biphenyl & 1.36 & 0.99 & 0 & 0.26 & 1.342 \\
\hline 5 & Aniline & 0.955 & 0.96 & 0.26 & 0.41 & 0.8162 \\
\hline 6 & Benzene & 0.61 & 0.52 & 0 & 0.14 & 0.7164 \\
\hline 7 & Toluene & 0.601 & 0.52 & 0 & 0.14 & 0.8573 \\
\hline 8 & 4-nitrotoluene & 0.87 & 1.11 & 0 & 0.28 & 1.0315 \\
\hline 9 & Anisole & 0.708 & 0.75 & 0 & 0.29 & 0.916 \\
\hline 10 & Bromobenzene & 0.882 & 0.73 & 0 & 0.09 & 0.8914 \\
\hline 11 & Chlorobenzene & 0.718 & 0.65 & 0 & 0.07 & 0.8388 \\
\hline 12 & 2-nitroaniline & 1.18 & 1.37 & 0.3 & 0.36 & 0.9904 \\
\hline 13 & 3-nitroaniline & 1.2 & 1.71 & 0.4 & 0.35 & 0.9904 \\
\hline 14 & 4-nitroaniline & 1.22 & 1.91 & 0.42 & 0.38 & 0.9904 \\
\hline 15 & Diphenylamine & 1.585 & 0.88 & 0.1 & 0.57 & 1.424 \\
\hline 16 & Pyridine & 0.631 & 0.84 & 0 & 0.52 & 0.6753 \\
\hline 17 & n-butylbenzene & 0.6 & 0.51 & 0 & 0.15 & 1.28 \\
\hline 18 & Iodobenzene & 1.188 & 0.82 & 0 & 0.12 & 0.975 \\
\hline 19 & 2-nitrotoluene & 0.866 & 1.11 & 0 & 0.27 & 1.032 \\
\hline 20 & Acetophenone & 0.818 & 1.01 & 0 & 0.48 & 1.0139 \\
\hline 21 & $\mathrm{~N}$-methylaniline & 0.948 & 0.9 & 0.17 & 0.43 & 0.9571 \\
\hline 22 & $\mathrm{~N}, \mathrm{~N}$-dimethylaniline & 0.957 & 0.84 & 0 & 0.42 & 1.098 \\
\hline 23 & p-cresol & 0.82 & 0.87 & 0.57 & 0.32 & 0.916 \\
\hline 24 & 4-Methylpyridine & 0.598 & 0.75 & 0 & 0.58 & 0.816 \\
\hline 25 & Cyclohexanone & 0.403 & 0.86 & 0 & 0.56 & 0.861 \\
\hline 26 & 4-Xylene & 0.613 & 0.52 & 0 & 0.16 & 0.998 \\
\hline 27 & Phenol & 0.805 & 0.89 & 0.6 & 0.3 & 0.775 \\
\hline
\end{tabular}


Table 2 Variance-covariance matrix of solute descriptors used in LSER equation.

\begin{tabular}{cccccc}
\hline & $R_{2}$ & $\pi^{\mathrm{H} 2}$ & $\sum \alpha^{\mathrm{H} 2}$ & $\sum \beta^{\mathrm{H} 2}$ & $V_{x}$ \\
\hline$R_{2}$ & 1 & 0.535 & 0.245 & 0.074 & 0.621 \\
$\pi^{\mathrm{H} 2}$ & & 1 & 0.500 & 0.32 & 0.118 \\
$\sum \alpha^{\mathrm{H} 2}$ & & & 1 & 0.158 & -0.126 \\
$\sum \beta^{\mathrm{H} 2}$ & & & & 1 & 0.020 \\
$V_{x}$ & & & & & 1 \\
\hline
\end{tabular}


Table 3 System coefficients of NFcS and C18.

\begin{tabular}{cccccccccccc}
\hline \multirow{2}{*}{ Column } & Eluent, acetonitrile-water $(\%, \mathrm{v} / \mathrm{v})$ & $c$ & $r$ & $s$ & $a$ & $b$ & $v$ & $R$ & $n$ & $S E$ & $F$ \\
\hline \multirow{3}{*}{$\mathrm{NFcS}$} & $80 \%$ & -0.556 & -0.030 & 0.036 & 0.024 & 0.284 & -0.235 & 0.948 & 27 & 0.031 & 89 \\
& $70 \%$ & -0.527 & -0.011 & 0.006 & 0.000 & 0.358 & -0.251 & 0.958 & 27 & 0.034 & 87 \\
& $60 \%$ & -0.503 & -0.012 & -0.005 & 0.004 & 0.226 & -0.134 & 0.942 & 27 & 0.026 & 42 \\
& $80 \%$ & -0.35 & 0.21 & -0.15 & -0.1 & -0.38 & 0.6 & 0.978 & 37 & 0.02 & 138 \\
\multirow{3}{*}{ Unisil C18 } & $70 \%$ & -0.34 & 0.24 & -0.19 & -0.13 & -0.53 & 0.78 & 0.982 & 37 & 0.03 & 167 \\
& $60 \%$ & -0.37 & 0.28 & -0.21 & -0.18 & -0.69 & 1 & 0.987 & 37 & 0.03 & 228 \\
\hline
\end{tabular}

$R$ : overall correlation coefficient; $\mathrm{n}$ : number of solutes; SE: standard error in the estimate; F: statistic.a Values obtained from Ref. [37]. 
Table 4 Comparison of $k, \alpha$ and $R$ of analytes on NFcS and ODS.

\begin{tabular}{|c|c|c|c|c|c|c|c|c|c|}
\hline \multirow{3}{*}{ Analytes } & \multicolumn{6}{|c|}{$\mathrm{NFcS}$} & \multirow{2}{*}{\multicolumn{3}{|c|}{$\frac{\text { ODS }}{\text { RP-HPLC }^{\mathrm{a}}}$}} \\
\hline & \multicolumn{3}{|c|}{ RP-HPLC ${ }^{a}$} & \multicolumn{3}{|c|}{ NP-HPLC ${ }^{b}$} & & & \\
\hline & $k$ & $\alpha$ & $R$ & $k$ & $\alpha$ & $R$ & $k$ & $\alpha$ & $R$ \\
\hline Benzene & 0.12 & - & - & 0.06 & - & - & 5.24 & - & - \\
\hline Naphthalene & 0.33 & 2.77 & 3.65 & 0.22 & 3.64 & 1.73 & 17.78 & 3.39 & 45.21 \\
\hline Phenanthrene & 0.85 & 2.56 & 13.95 & 0.52 & 2.40 & 2.90 & 64.07 & 3.60 & 57.63 \\
\hline Pyrene & 1.35 & 1.58 & 7.06 & 0.83 & 1.58 & 2.40 & 91.93 & 1.43 & 9.86 \\
\hline Chrysene & 2.02 & 1.49 & 4.14 & 1.27 & 1.53 & 2.84 & 98.18 & 1.07 & 1.43 \\
\hline \multirow[t]{3}{*}{ Benzo[j]fluoranthene } & 3.20 & 1.59 & 3.95 & 1.69 & 1.34 & 2.27 & / & / & / \\
\hline & \multicolumn{3}{|c|}{ RP-HPLC ${ }^{c}$} & \multicolumn{3}{|c|}{ NP-HPLC ${ }^{b}$} & \multicolumn{3}{|c|}{ RP-HPLC ${ }^{c}$} \\
\hline & $k$ & $\alpha$ & $R$ & $k$ & $\alpha$ & $R$ & $k$ & $\alpha$ & $R$ \\
\hline Benzene & 0.32 & - & - & 0.05 & - & - & 9.25 & - & - \\
\hline Toluene & 0.52 & 1.62 & 2.63 & 0.05 & I & / & 36.81 & 3.98 & 11.03 \\
\hline Bromobenzene & 0.94 & 1.81 & 3.83 & 0.15 & 3.00 & 1.08 & / & l & I \\
\hline \multirow[t]{3}{*}{ Iodobenzene } & 1.43 & 1.52 & 3.00 & 0.15 & l & I & / & / & / \\
\hline & \multicolumn{3}{|c|}{ RP-HPLC ${ }^{c}$} & \multicolumn{3}{|c|}{ NP-HPLC ${ }^{\mathrm{d}}$} & \multicolumn{3}{|c|}{ RP-HPLC ${ }^{c}$} \\
\hline & $k$ & $\alpha$ & $R$ & $k$ & $\alpha$ & $R$ & $k$ & $\alpha$ & $R$ \\
\hline Aniline & 0.23 & - & - & 0.03 & - & - & 5.72 & - & - \\
\hline $\mathrm{N}, \mathrm{N}$-dimethyl aniline & 0.53 & 2.33 & 4.48 & 0.22 & 6.67 & 1.98 & 12.58 & 2.20 & 30.15 \\
\hline 4-Nitroaniline & 0.70 & 1.33 & 2.13 & 0.59 & 2.70 & 2.85 & 25.40 & 2.02 & 34.32 \\
\hline Benzidine & 1.44 & 2.05 & 4.16 & 2.96 & 5.02 & 8.20 & 103.25 & 4.07 & 39.00 \\
\hline \multirow[t]{3}{*}{ Diphenylamine } & 2.76 & 1.92 & 2.35 & 5.51 & 1.86 & 3.36 & I & I & l \\
\hline & \multicolumn{3}{|c|}{ RP-HPLC ${ }^{c}$} & \multicolumn{3}{|c|}{ NP-HPLC ${ }^{\mathrm{e}}$} & \multicolumn{3}{|c|}{ RP-HPLC ${ }^{c}$} \\
\hline & $k$ & $\alpha$ & $R$ & $k$ & $\alpha$ & $R$ & $k$ & $\alpha$ & $R$ \\
\hline 4-Cyanopyridine & 0.16 & - & - & 1.12 & 0.11 & 3.62 & 3.25 & 1.19 & 1.98 \\
\hline 2-Bromopyridine & 0.40 & 2.42 & 4.45 & 0.61 & - & - & 11.81 & 3.63 & 22.90 \\
\hline 3, 5-Lutidine & 0.58 & 1.44 & 2.79 & 0.61 & I & l & 38.63 & 3.27 & 12.76 \\
\hline 4-Hydroxypyridine & 1.10 & 1.91 & 6.35 & 4.81 & 0.96 & 0.48 & 2.74 & 16.15 & 15.24 \\
\hline \multirow[t]{3}{*}{ 4-Pyridinethiol } & 2.09 & 1.91 & 8.12 & 4.37 & 0.73 & 7.03 & 0.17 & - & - \\
\hline & \multicolumn{3}{|c|}{ RP-HPLC ${ }^{c}$} & \multicolumn{3}{|c|}{ NP-HPLC ${ }^{f}$} & \multicolumn{3}{|c|}{ RP-HPLC ${ }^{c}$} \\
\hline & $k$ & $\alpha$ & $R$ & $k$ & $\alpha$ & $R$ & $k$ & $\alpha$ & $R$ \\
\hline 4-Hydroxyquinoline & 0.82 & - & - & 0.22 & - & - & 2.24 & - & - \\
\hline Quinoline & 1.02 & 1.25 & 2.69 & 0.22 & I & / & 15.81 & 7.05 & 5.27 \\
\hline 2-Methylquinoline & 1.25 & 1.23 & 2.64 & 0.22 & I & l & 32.78 & 2.07 & 4.40 \\
\hline \multirow[t]{3}{*}{ 4-Methylquinoline } & 1.56 & 1.25 & 2.80 & 6.36 & 29.10 & 8.55 & 36.72 & 1.12 & 1.61 \\
\hline & \multicolumn{3}{|c|}{ RP-HPLC ${ }^{g}$} & & P-HPL & & & P-HPL & \\
\hline & $k$ & $\alpha$ & $R$ & $k$ & $\alpha$ & $R$ & $k$ & $\alpha$ & $R$ \\
\hline 2-Cresol & 0.17 & - & - & 0.44 & - & - & 0.03 & - & - \\
\hline Resorcinol & 0.35 & 2.07 & 1.30 & 1.01 & 2.28 & 2.46 & 0.78 & 28.52 & 12.58 \\
\hline 1-Naphthol & 0.58 & 1.64 & 1.36 & 4.40 & 4.36 & 4.19 & 1.02 & 1.30 & 3.38 \\
\hline 3-Nitrophenol & 3.07 & 5.30 & 9.01 & 6.10 & 1.39 & 1.20 & 2.16 & 2.11 & 13.00 \\
\hline & & P-HPL & & & P-HPL & & & P-HPL & \\
\hline & $k$ & $\alpha$ & $R$ & $k$ & $\alpha$ & $R$ & $k$ & $\alpha$ & $R$ \\
\hline
\end{tabular}




\begin{tabular}{cccccccccc}
\hline Cytosine & 0.18 & - & - & $/$ & $/$ & $/$ & 0.18 & - & - \\
Acyclovir & 0.29 & 1.65 & 2.44 & $/$ & $/$ & $/$ & 0.18 & $/$ & $/$ \\
Adenine & 0.55 & 1.87 & 3.59 & $/$ & $/$ & $/$ & 0.29 & 1.66 & 1.76 \\
6-Chloropurine & 2.07 & 3.75 & 9.53 & $/$ & $/$ & $/$ & 0.29 & $/$ & $/$ \\
\hline
\end{tabular}

I: $\alpha$ and $R$ can not be calculated because compounds were not selected as analyte.

${ }^{\text {a }}$ Acetonitrile-water $\left(35 / 65\right.$, v/v); flow rate, $1 \mathrm{~mL} / \mathrm{min}$; detection wavelength, $254 \mathrm{~nm}$; column temperature, $30{ }^{\circ} \mathrm{C}$.

${ }^{\mathrm{b}}$ Hexane $(100 \%)$; flow rate, $1 \mathrm{~mL} / \mathrm{min}$; detection wavelength, $254 \mathrm{~nm}$; column temperature, $30{ }^{\circ} \mathrm{C}$.

${ }^{\mathrm{c}}$ Acetonitrile-water $(10 / 90, \mathrm{v} / \mathrm{v})$; flow rate, $1 \mathrm{~mL} / \mathrm{min}$; detection wavelength, $254 \mathrm{~nm}$; column temperature, $30{ }^{\circ} \mathrm{C}$.

${ }^{\mathrm{d}}$ Hexane-isopropanol (70/30, v/v); flow rate, $1 \mathrm{~mL} / \mathrm{min}$; detection wavelength, $254 \mathrm{~nm}$; column temperature, 30 ${ }^{\circ} \mathrm{C}$.

${ }^{\mathrm{e}}$ Hexane-isopropanol (90/10, v/v); flow rate, $1 \mathrm{~mL} / \mathrm{min}$; detection wavelength, $254 \mathrm{~nm}$; column temperature, 30 ${ }^{\circ} \mathrm{C}$.

${ }^{\mathrm{f}}$ Hexane-isopropanol (70/30, v/v); flow rate, $1 \mathrm{~mL} / \mathrm{min}$; detection wavelength, $254 \mathrm{~nm}$; column temperature, 30 ${ }^{\circ} \mathrm{C}$.

${ }^{\mathrm{g}}$ Methanol-water $(60 / 40, \mathrm{v} / \mathrm{v})$; flow rate, $1 \mathrm{~mL} / \mathrm{min}$; detection wavelength, $254 \mathrm{~nm}$; column temperature, $30{ }^{\circ} \mathrm{C}$.

${ }^{\mathrm{h}}$ Acetonitrile-water (55/45, v/v); flow rate, $1 \mathrm{~mL} / \mathrm{min}$; detection wavelength, $260 \mathrm{~nm}$; column temperature, $30{ }^{\circ} \mathrm{C}$. 
Table 5 The linearity equation, $\mathrm{R}^{2}$, LOD and LOQ of two PGRs on NFcS column.

\begin{tabular}{ccc}
\hline Analyte & benzthiazuron & forchlorfenuron \\
\hline Linearity equation & $y=69.271 x+9.5031$ & $y=252.05 x+26.225$ \\
Regression coefficient $\mathrm{R}^{2}$ & 0.99998 & 0.99997 \\
LOD $(\mu \mathrm{g} / \mathrm{mL})$ & 0.03 & 0.01 \\
LOQ $(\mu \mathrm{g} / \mathrm{mL})$ & 0.10 & 0.04 \\
\hline
\end{tabular}




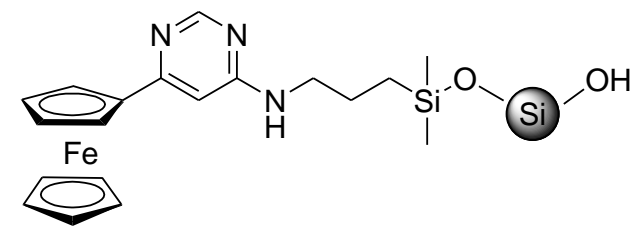

Fig. 1. Chemical structure of the 4-chloro-6-pyrimidinylferrocene bonded silica stationary phase (NFcS). 


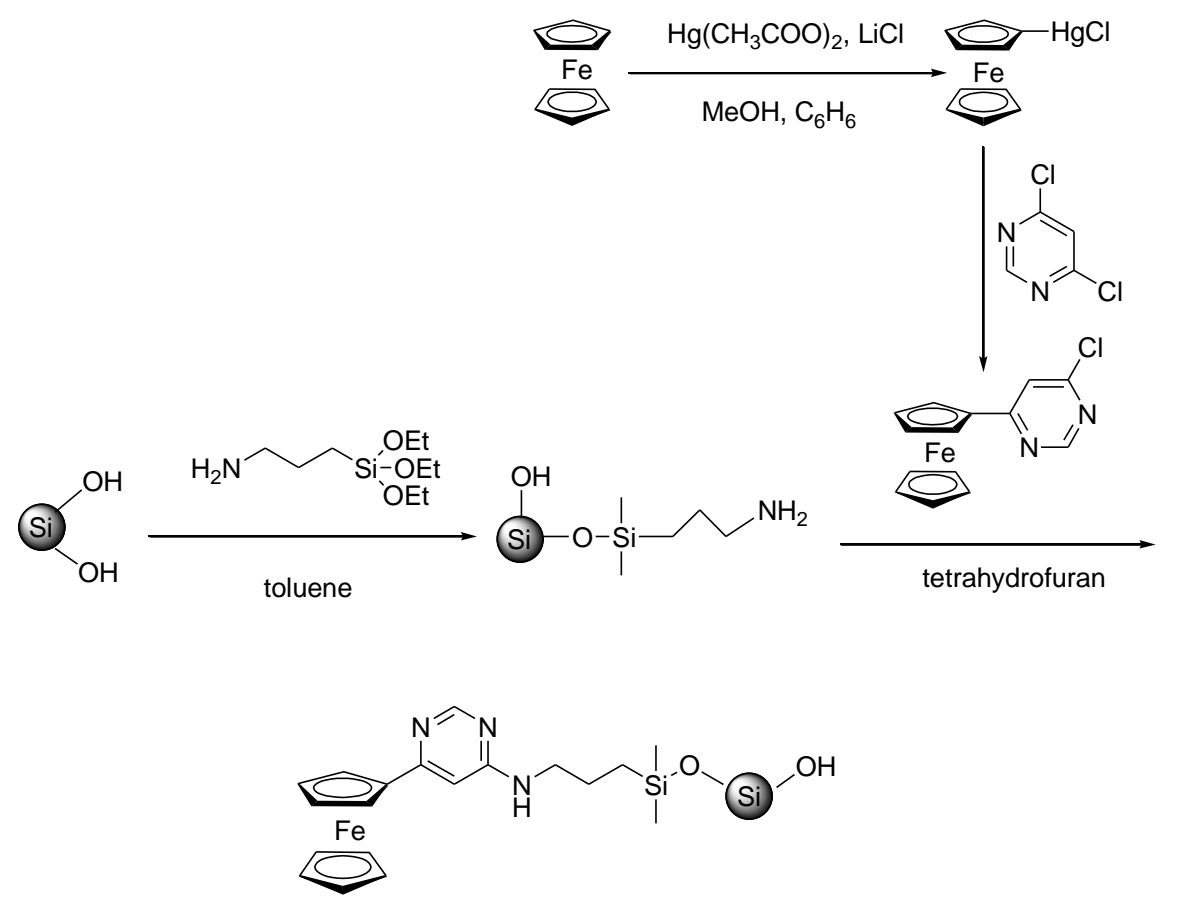

Fig. 2. Preparation scheme of the NFcS stationary phase. 


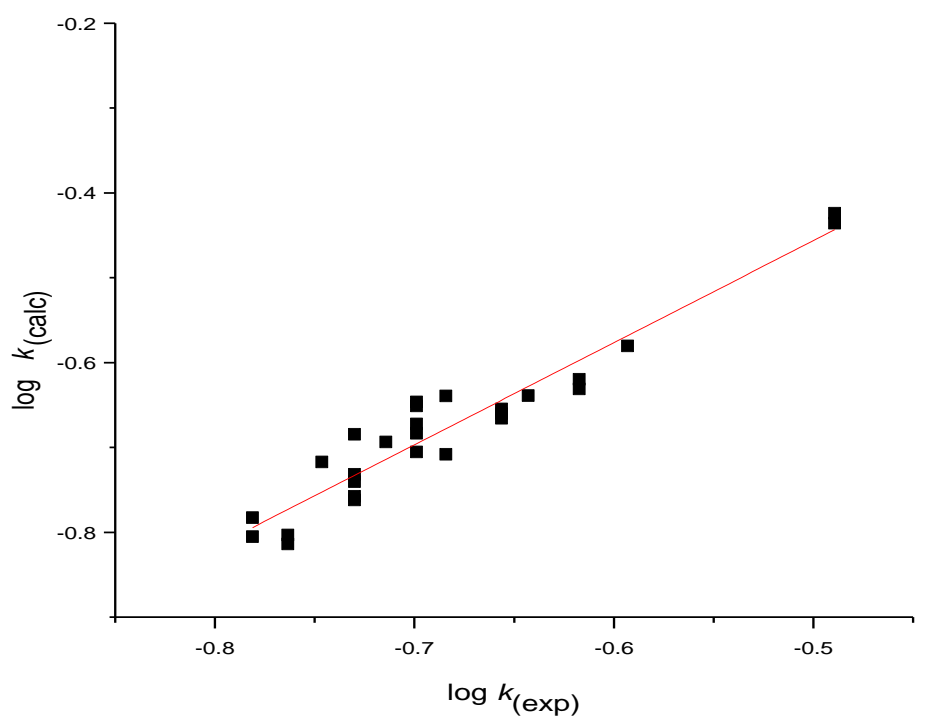

Fig. 3. Plot depicting $\log k($ calc $)$ versus $\log k(\exp )$ with $80 / 20$ (v/v) acetenitrile/water. 


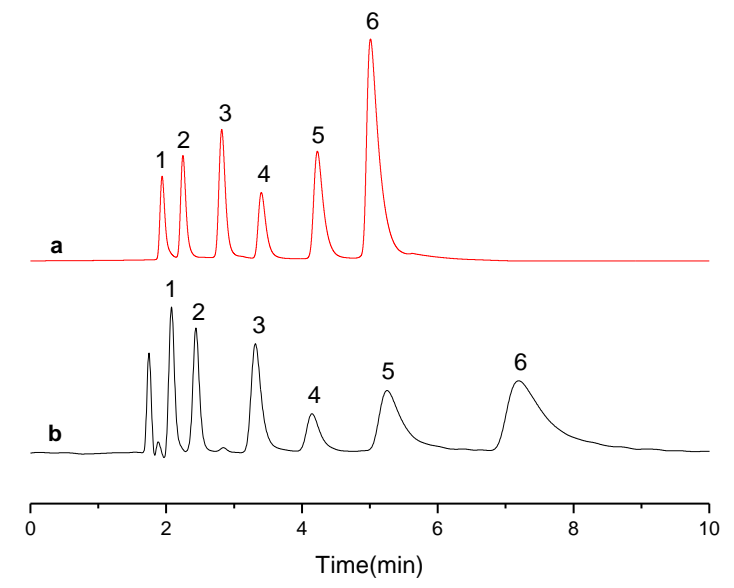

Fig. 4. Chromatograms of PAHs on NFcS in (a) NP-HPLC and (b) RP-HPLC condition.

Mobile phase: (a) hexane (100\%); flow rate, $1 \mathrm{~mL} / \mathrm{min}$; detection wavelength, $254 \mathrm{~nm}$; column temperature, $30{ }^{\circ} \mathrm{C}$. (b) methanol-water $(60 / 40, \mathrm{v} / \mathrm{v})$; flow rate, $1 \mathrm{~mL} / \mathrm{min}$; detection wavelength, $254 \mathrm{~nm}$; column temperature, $30^{\circ} \mathrm{C}$. Peaks: 1 , benzene; 2 , naphthalene; 3 , phenanthrene; 4, pyrene; 5 , chrysene; 6 , benzo[j]fluoranthene. 


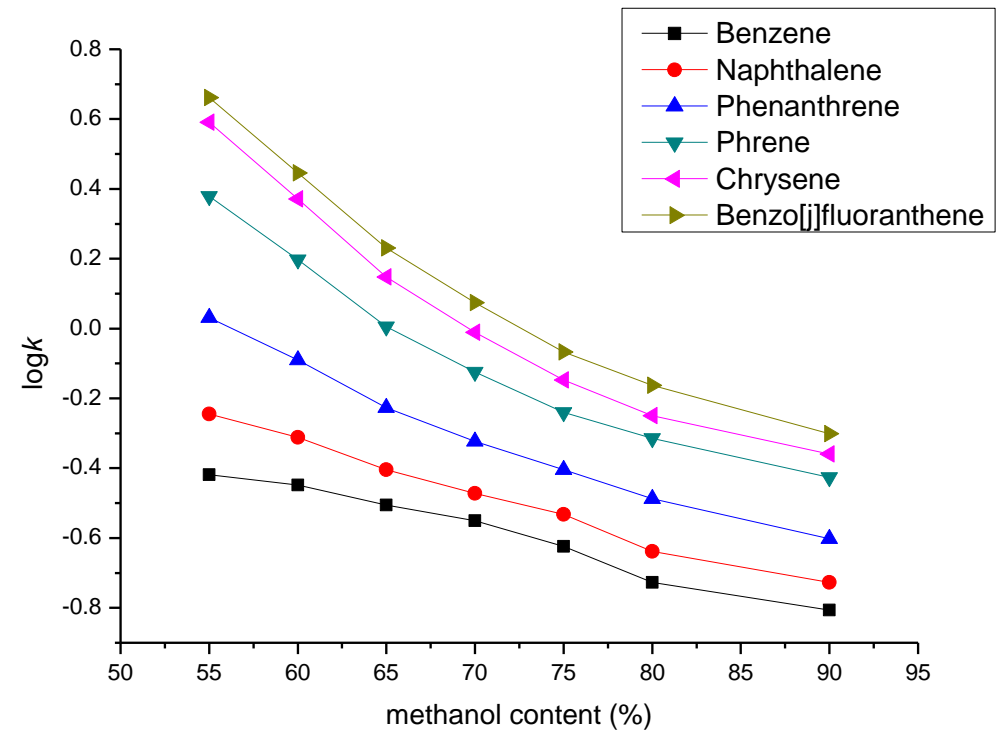

Fig. 5. Effect of methanol content on $\log k$ of PAHs on NFcS column. Conditions: mobile phase, different methanol contents; flow rate, $1.0 \mathrm{~mL} / \mathrm{min}$; detection wavelength, $254 \mathrm{~nm}$; column temperature, $30{ }^{\circ} \mathrm{C}$. 


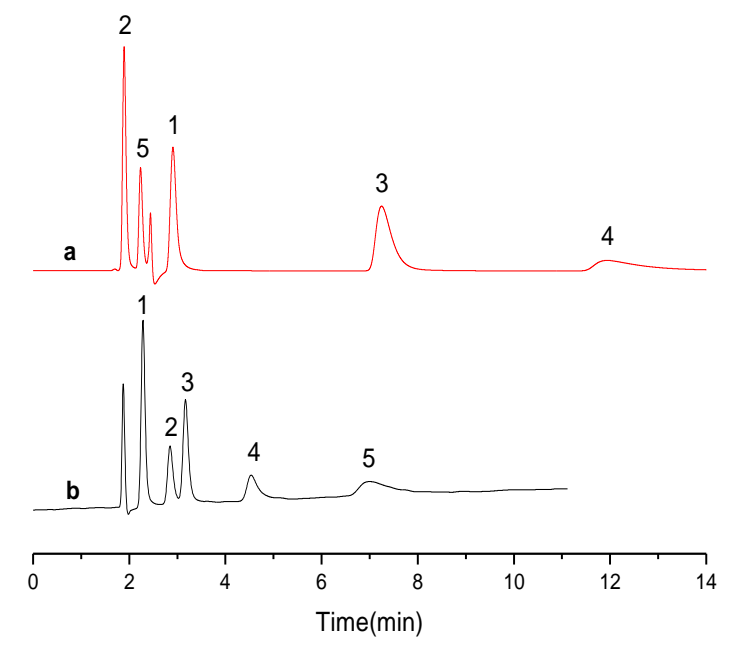

Fig. 6. Chromatograms of aniline mixtures on NFcS column in (a) NP-HPLC and (b) RP-HPLC conditions. Mobile phase: (a) hexane-isopropanol (70/30, v/v); flow rate, $1 \mathrm{~mL} / \mathrm{min}$; detection wavelength, $254 \mathrm{~nm}$; column temperature, $30{ }^{\circ} \mathrm{C}$. (b) acetonitrile-water (10/90, v/v); flow rate, $1 \mathrm{~mL} / \mathrm{min}$; detection wavelength, $254 \mathrm{~nm}$; column temperature, $30{ }^{\circ} \mathrm{C}$. Peaks: 1, aniline; 2, N, N-dimethyl aniline; 3, 4-nitroaniline; 4, benzidine; 5, diphenylamine. 


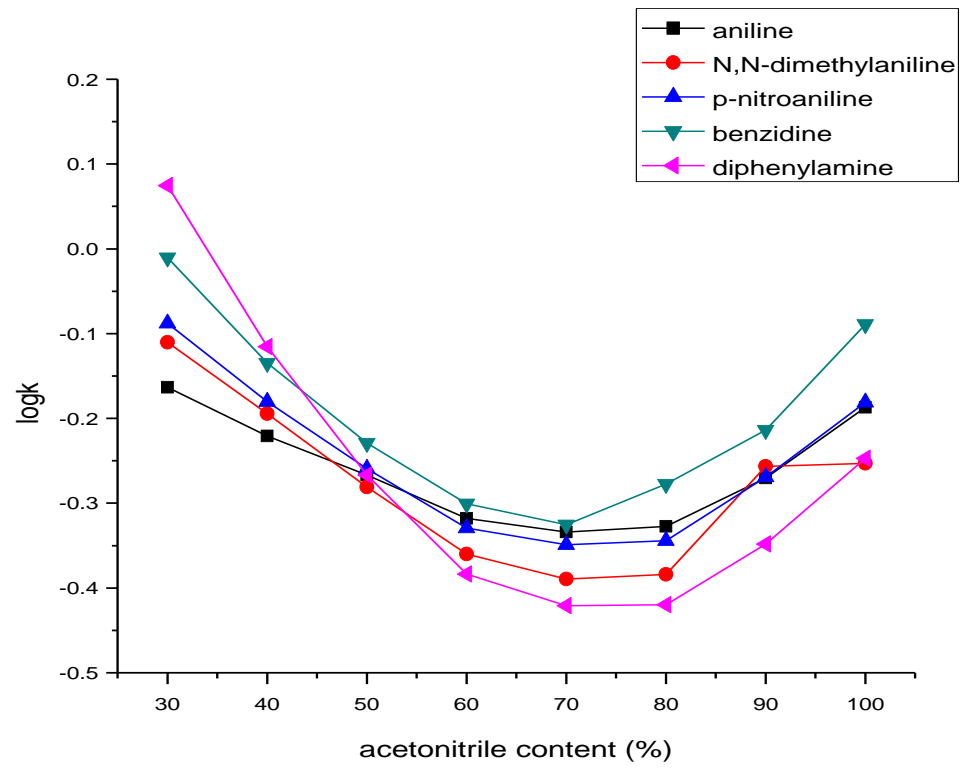

Fig. 7. Effect of acetonitrile content on the retention of aromatic compounds. Conditions: mobile phase, different acetonitrile contents; flow rate, $1.0 \mathrm{~mL} / \mathrm{min}$; detection wavelength, $254 \mathrm{~nm}$; column temperature, $30{ }^{\circ} \mathrm{C}$. 

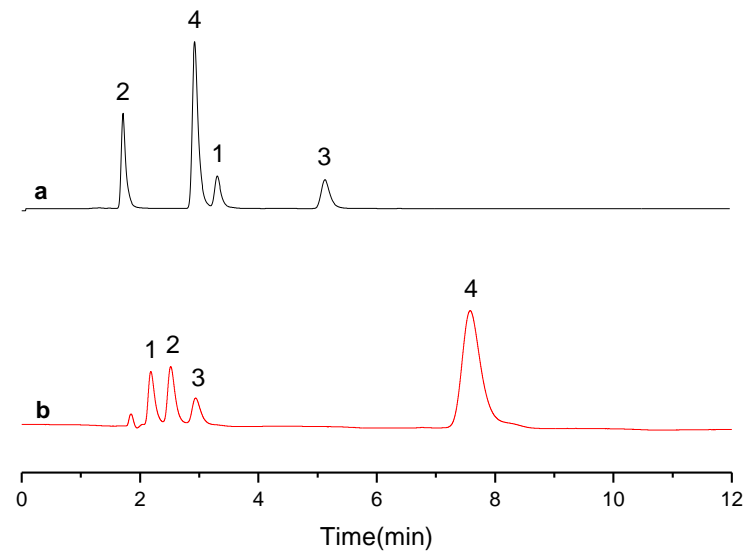

Fig. 8. Chromatograms of phenols on (a) ODS and (b) NFcS.

Mobile phase: methanol-water (60/40, v/v); flow rate, $1.0 \mathrm{~mL} / \mathrm{min}$; detection wavelength, $254 \mathrm{~nm}$; column temperature, $30{ }^{\circ} \mathrm{C}$. Peaks: 1, 2-cresol; 2, resorcinol; 3, 1-naphthol; 4, 3-nitrophenol. 


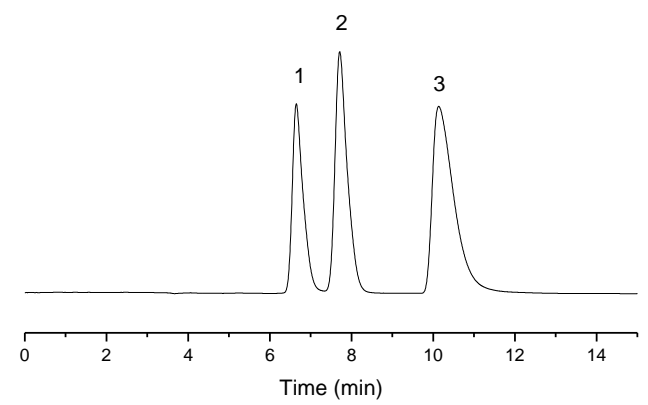

Fig. 9. Chromatograms of inorganic anions on $\mathrm{NFcS}$.

Mobile phase: $25 \mathrm{mmol} \mathrm{L}^{-1} \mathrm{KCl}$ aqueous solution (pH 6.8), flow rate, $0.5 \mathrm{~mL} / \mathrm{min}$; detection wavelength, $210 \mathrm{~nm}$; column temperature, $30{ }^{\circ} \mathrm{C}$. Peaks: 1 , iodate; 2 , nitrate; 3 , thiocyanate. 


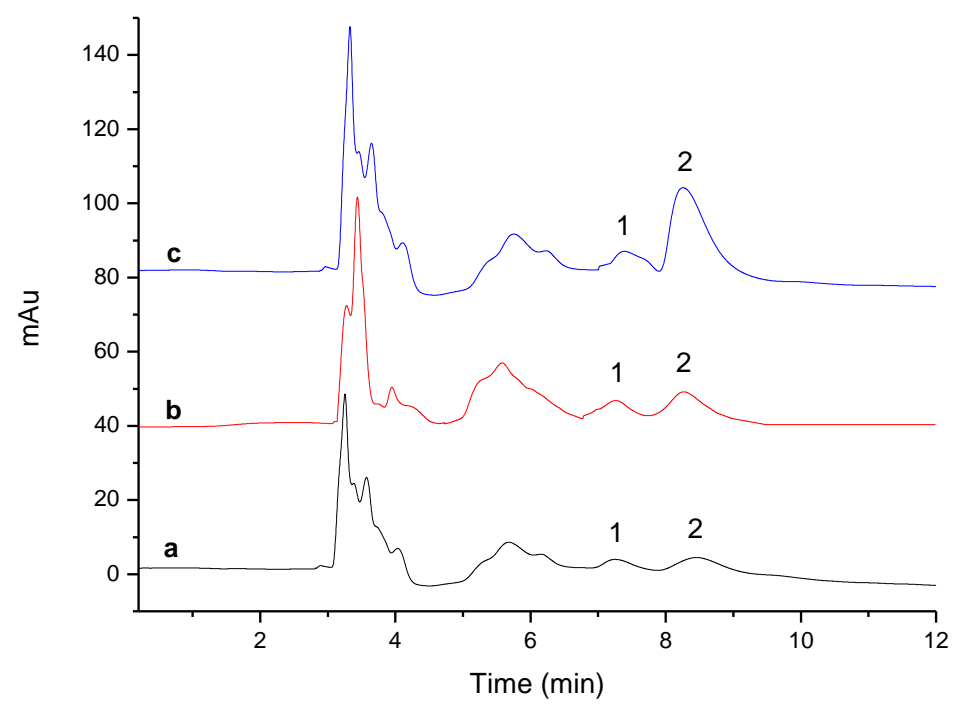

Fig. 10. Chromatogram of two PGRs in grapes on $\mathrm{NFcS}$ column.

Mobile phase: acetonitrile-water $(20 / 80, \mathrm{v} / \mathrm{v})$; flow rate, $1 \mathrm{~mL} / \mathrm{min}$; detection wavelength, $254 \mathrm{~nm}$; column temperature, $30{ }^{\circ} \mathrm{C}$. (a) grape; (b) spiked grape; (c) $2 \mu \mathrm{g} / \mathrm{mL}$ standard solution. Peaks: 1. benzthiazuron; 2. forchlorfenuron. 


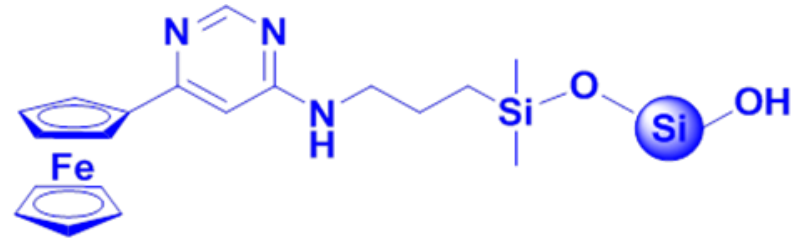

$\square$ mixed-mode chromatography

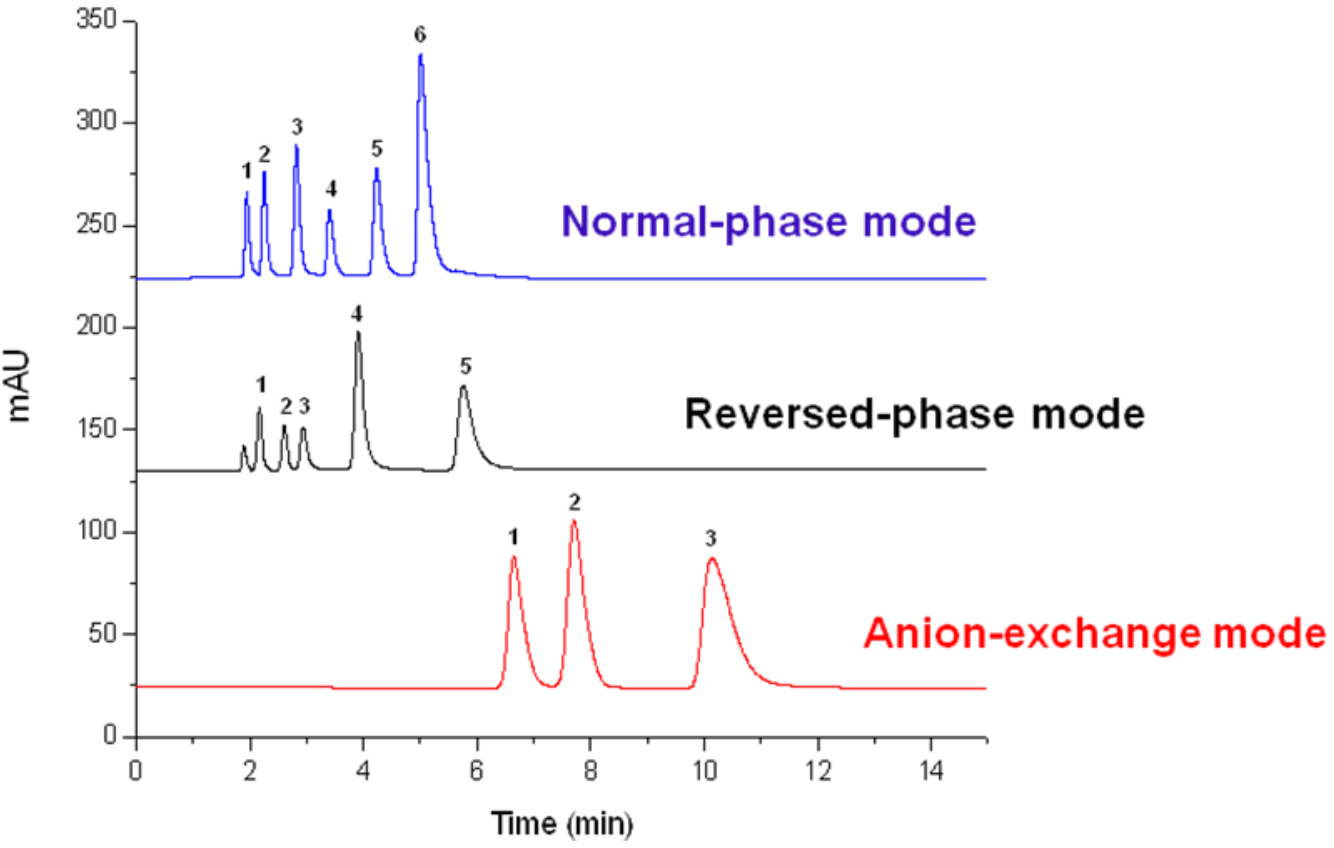

